\title{
POESIA BRASILEIRA CONTEMPORÂNEA, PAISAGEM E MEMÓRIA
}

CONTEMPORARY BRAZILIAN POETRY, MEMORY AND LANDSCAPE

\author{
Maria Luiza Berwanger da Silva ${ }^{1}$
}

Resumo: Com base na reflexão teórica de Michel Collot sobre os estudos da Paisagem, este artigo evidencia a eficácia do "pensamento-paisagem" para a produção de cruzamentos, hibridismos e trânsitos operados pela relação: literatura e outras linguagens. Nesse sentido, examina fragmentos da poesia brasileira contemporânea de José Horácio Costa, de Haroldo de Campos, de Ana Cristina César, de Manoel de Barros, de Adélia Prado e de Marcos Siscar, nos quais verifica a produtividade de dois eixos articuladores do "pensamento-paisagem": o da percepção, como redescoberta de espaços enigmáticos do sujeito, $e$ o da paisagem, como substituição da representação pela experiência paisagística da presença. Conclui-se que, uma vez postos em intersecção, esses dois eixos configuram a composição de uma paisagem intervalar, resultante das relações da literatura com a geografia, mediada pelas diferentes redefinições processadas pelo sujeito que, enquanto presença, se inventa, reinventando a paisagem. Palavras-chave: paisagem; pensamento; subjetividade; memória

Abstract: This article is based on the theoretical thinking of Michel Collot about the studies of the landscape, to put on evidence the efficacy of "pensée-paysage" to create the crossings, hybridisms and transits operated by the relationship between literature and other languages. In this objective, it examines poetic fragments from José Horácio Costa, Haroldo de Campos, Ana Cristina César, Manoel de Barros, Adélia Prado and Marcos Siscar to verify the productivity of two main axes of "pensée-paysage". One axis as a perception of a rediscovery of enigmatic spaces from the subject and the other one as a replacement of a geographic representation by the landscape experience coming from the presence. So, the intersection of these two axes configures the composition of one intermediate landscape from the relationships of literature and geography mediated by different redefinitions processed by the subject over himself as well as over the landscape.

Keywords: landscape; thinking; subjectivity; memory

1 Professora, Pesquisadora e Orientadora do Programa de Pós-Graduação em Letras da Universidade Federal do Rio Grande do Sul, desde 1996, e do Programa de Pós-Graduação de Memória Social e Bens Culturais do Instituto Unilasalle, desde 2014. 
Este é o mapa. Onde quer que você se encontre onde quer que você se perca. Este é o mapa. O que você diz e pensa é o mapa. O mapa é maleável sujeito a invasões bloqueios ou decisões políticas e graves extravios. O mapa está contido em suas incontinências. Aqui e em toda a parte.

Estradas do bonde campinas de pedreira horizontes de amparo. O mapa é este. A vida é esta datada e situada com palavras. Mas o sentido da cartografia precisa mais do que o anúncio a biografia a estética a política do mapa. Nada consegue impedir a profusão dos mapas as rasuras do mapa.

Meu jardim por exemplo é um mapa por onde se desce. Desço até o jardim por uma escada. Folheio o jardim como quem se lembra. Ele é a sinopse de vários outros canteiros hortas pomares roseirais. Meu jardim me comporta e me distingue. Meu jardim revitaliza minhas palavras me sugere outras ocupações do solo.

Cada vez que planto ou que arranco que cubro ou desenterro de muito perto de uma proximidade orgânica com as próprias mãos com o rosto colado na terra fecho os olhos e vejo o mapa. Sinto a umidade do mapa. Tenho odores fortes de mato e cortes nas mãos. Faço movimentos bruscos ajusto contas até reduzir-me ao chão.

O céu é a dobra natural do meu jardim. Uma geografia de altos relevos de vaporização e desfiguração de descontextualizações ferozes. $\mathrm{O}$ ar me impõe deslocamentos de lugares e de datas a volatilidade dos mapas. Dali de cima a terra está solta pronta para sair de sua órbita e cair no abismo cósmico. A vertigem é meu parapeito.

(Siscar, 2015, p. 97)

Cartografia mínima, poema de encerramento de Manual de flutuação para amadores, de Marcos Siscar (2015), traça, sobre a página, o desenho de uma paisagem singular: nomeia a ressimbolização de um espaço, tornando-o transterritorial, do mesmo modo que transforma o tempo em vivência imemorial, contrapondo-se ao simbolismo de "mínima”, no título 
do poema. Vista sob esse efeito lírico que trai a abrangência da visibilidade, Cartografia mínima sinaliza o traçado de certo perscrutar, no rastro de tantas outras vozes poéticas constitutivas da poesia brasileira contemporânea.

Confluentes no projeto de transgredir fronteiras geográficas e sensíveis estabelecidas, nessas vozes, lugares, memórias e nacionalidades cristalizadas são desmarcados que retecem novos mapas pela força do pensamento; como se essa inclinação da poética contemporânea requeresse o direito de uma infatigável errância; como se, igualmente, ao fazê-lo, o poeta fosse compondo o esboço de certo território intervalar, no qual distintas linguagens convivem em relação de suave harmonia com a literatura mediada pela relação do livre pensar com o livre perceber. Desse modo, toda busca de apreensão dessa "cartografia mínima" ampliada incide no perscrutar da própria subjetividade, enquanto movimento do olhar que, ao processar a decantação do real circundante, processa, igualmente, operações de transformação, gerando inusitados convívios entre literatura e outras linguagens, postas em intersecção. No presente artigo, a leitura simbólica de fragmentos poéticos do Brasil contemporâneo evidenciará uma amostragem desse conjunto de novos modos e formas de relações emergentes do entrelaçamento entre literatura e geografia traduzidas pela percepção do Mesmo, em Haroldo de Campos, pela dança em Ana Cristina César, pela fauna e pela flora do Pantanal em Manoel de Barros, pela percepção do Outro em Armando Freitas Filho, pela figura de espaço e tempo entremeados em Adélia Prado, pelo jogo entre paisagens distintas em José Horácio Costa e pelo redesenhar de certo "jardim" em Marcos Siscar. (Veja-se, sob o traçado dessa constelação poética apresentada, o próprio itinerário de busca de reencantamento de lugares, memórias e subjetividades, articuladas pelo "pensamento-paisagem" enquanto dispositivo que dá a ver os bastidores das operações de relação efetuadas por literatura e geografia.)

Nota-se, no retecer desses fios textuais poéticos e geográficos aproximados, o projeto inconfesso de marcar a distância percorrida pela palavra em busca voluntária de se autoliberar da sedução exercida pela geografia tropical. Desmarcar esta distância corresponde a perceber a configuração de certa paisagem intervalar, produto das operações subjetivas acionadas. Assim composta, a poesia brasileira contemporânea, perspectivada pela voz-síntese de Marcos Siscar, encontra legitimidade teórico-crítica nos estudos sobre a Paisagem articulados pelo crítico e poeta Michel Collot, principalmente na reflexão desenvolvida em Pensée-Paysage (2011).

Nessa obra, dois conjuntos de perspectivas entrecruzadas fazem-se eficazes para o exame da textualidade poética brasileira, hoje: um conjunto Organon, Porto Alegre, v. 31, n. 61, p. 65-80, jul/dez. 2016. 
de afirmações referentes à delimitação da "pensée-paysage" como "ni pure représentation ni une simple présence mais un entrecroisement entre les deux" (p. 18), como "espace transitionnel entre l'intérieur et l'extérieur, le réel et l'imaginaire" (p. 30), como "migration indéfinie qui lui est intérieure" (p. 133), a que se entrelaça um outro conjunto de configurações referentes à atividade do sujeito, tais como o fato de que "le paysage implique un sujet qui ne réside plus en lui-même, mais qui s'ouvre au dehors" (p. 33), de que a incidência sobre o espaçamento do sujeito "permet de figurer l'infigurable" (p. 132), e decifra o "fond insondable du paysage" (p. 135). Postos em intersecção, esses eixos acenam para a relação singular que se estabelece entre diferentes linguagens aproximadas sob forma de "distância consentida" que versos de Marcos Siscar traduzem com exemplaridade:

qual é a distância certa da cidade? a altura
certa para ver a cidade? de onde a cidade
não seja apenas vista de onde não seja apenas
memória de outra ou miragem pressentida
meu desejo desta tarde é o da distância certa
uma troca de indícios uma ideia de alegria
não a ilusão panorâmica do que é visível
mas a distância consentida ali onde se aceita
a invenção da vida as insinuações da morte
a camada de mortos e de vivos sob a vasta
construção em curso desejo de cidade
me pergunto onde estou e qual a distância certa
mas não há nada além ou aquém desta
sacada leste nenhuma silhueta que passe
kaváfis ligeira sobre o topo das colinas

(Siscar, 2015, p. 22)

Desse modo, retrair, condensando, a distância entre sujeito e real circundante corresponde a legitimar a reflexão de Michel Collot nas palavras, quando diz:

Si le paysage est un art, il ne se limite pas à la sphère des représentations : il commence in situ, et à ras de terre, avec la culture du sol et des végétaux. Le paysagiste est à la fois artiste, ingénieur et paysan : un artisan inspiré, un créateur terre à terre. Homme d'atelier et de terrain, il assume tour à tour la conception du projet, sa réalisation et son suivi. Il réinvente à sa manière l'un des sens du mot art, qui ne dissocie pas la technique d'une visée esthétique. Il mobilise 
ainsi une pensée qui noublie jamais le concret, pour produire une œuvre à la fois sensible et intelligible, lisible et visible pour l'œil du corps et celui de l'esprit - une pensée-paysage (Collot, 2011, p. 192),

significando sintetizar a plenitude da Pensée-Paysage pela valorização da experiência paisagística operada pela presença.

Acrescente-se, nesse sentido, tanto a prática da subjetividade evidenciada pela presença que retoma, a seu modo, a articulação da experiência nomeada por Julia Kristeva como dupla dimensão de passividade e de atividade ("une expérience est toujours un rapport au dehors, à un dehors du discours, ou de la langue, ou du corps, ou de la croyance" (Kristeva, 2005, p. 155$)^{2}$, quanto a "guinada subjetiva" evidenciada por Beatriz Sarlo em Tempo passado (2007), em reflexão que amplia a eficácia da vivência conquanto a configura como constante jogo entre o privado e o social; Beatriz Sarlo, assim pensando, instiga o prazer da narratividade múltipla, do dizer a paisagem como espetáculo da intimidade. Nela, justamente, a indistinção de tempo e espaço, enquanto imagens retidas pelo exercício da subjetividade, funda paisagens da memória como estampa singular da invenção, na base do livre perceber e do livre pensar. Logo, eleger a "pensée-paysage" nomeada por Michel Collot como eixo articulador da leitura do poema, na medida em que possibilita esta celebração da experiência da presença e do consequente efeito de ressimbolização do real circundante, faz-se pressuposto teórico-crítico passível de transferência e de sustentação ao itinerário traçado pela poesia brasileira contemporânea. Como bem a define Marcos Siscar em artigo publicado em Littérature du Brésil (Revue Europe, n. 919-920, 2005): “[...] Reste une nécessité, aujourd’hui, pour la poésie brésilienne : qu’elle fasse le pas vers son (avoir lieu). À la pensée, il revient d'accueillir ce souci de déplacement du poème en le laissant faire épreuve de ses nouveaux paradigmes [...]”. Tal perspectiva equivale a vislumbrar a "pensée-paysage" como uma das possíveis articulações de busca de consolidação do "avoir lieu”, considerando-o como ter lugar no nacional

2 “Il est essentiel à l'idée d'expérience qu’elle resulte d'une confrontation avec un élément étranger à soi-même, inconnu, ou à tout le moins impossible à certifier d'emblée dans toutes ses déterminations. Ce dont je dois faire l'expérience, c'est toujours ce que je ne peux ni simplement déduire ni connaître par avance avec certitude. En ce sens-là, il est évident qu’appartient au domaine de l'expérience la totalité de l'existence, où l'on trouvera pêle-mêle, si j’ose dire, la persistance et la consistance du réel, le désir de l'autre, le déroulement de l'histoire, la contingence et les surprises du hasard, etc." (Droit, 2005, p. 156). 
e no transnacional, bem como na diversidade de linguagens literárias e não literárias compartilhadas. Sob a égide da experiência vivenciada e da multiplicidade de reciclagens e ressimbolizações efetivadas pelo sujeito, o ajuste entre paisagem/memória e poesia efetiva-se pelo prazer da palavra que narra sobre a página os bastidores de seu dizer como estampa do livre perceber ressonâncias, nuanças e matizes tecidas, destecidas e retecidas pelo convívio da literatura e outras linguagens confrontadas. ${ }^{3}$

Figura-síntese do espaço brasileiro, visto em sua dimensão teórico-crítica e poética, Haroldo de Campos, poeta, tradutor, teórico da Literatura Comparada, traduz esta imagem do perceber como pensamento que nomeia a cartografia interior e que, ao fazê-lo, transforma representação ou figuração da paisagem em presença que busca decifrar o indecifrável de todo espaço paisagístico. Como diz Haroldo de Campos nos versos de Tenzone, de seu livro A educação dos cinco sentidos:

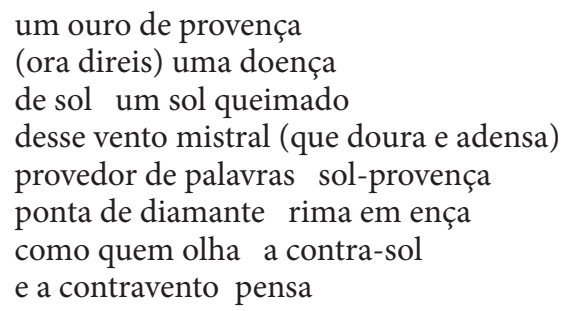

Cogolin Provence

(Campos, 1989, p. 58-59)

Neste poema, a evocação de um lugar longínquo (a Provença), ao sublinhar a produtividade dos "cinco sentidos" para o fazer poético, enquanto forma perceptiva plural, expressa um dos traços recorrentes da poesia brasileira contemporânea, expresso pelo simbolismo do "educar". (Veja-se sob esse simbolismo do educar, nesse poema, o filtro da exaltação à geografia tropical que possibilita à subjetividade projetar, sobre o espaço de fora, a melodia de sua paisagem íntima.) Assim procedendo, essa prática descobre cantos obtusos da paisagem a ser nomeada. Dito de outro modo: a paisagem adensa-se em Tenzone pela vivência e ressimbolização do efeito

3 Leia-se, sobre essa inclinação da produção brasileira atual, minhas publicações: BERWANGER DA SILVA, Maria Luiza. "Littérature Brésilienne Contemporaine: entre production et reflexion". In: BESSIÈRE, Jean (Org.). Littérature d'aujourd'hui : contemporain, innovatiom, partages culturels, politique, théorie littéraire. Paris: Honoré Champion, 2011, v. 17, p. 77-84 ; e BERWANGER DA SILVA, Maria Luiza. "Autorreflexividade e Invenção na Poesia Brasileira Contemporânea". In: BASTAGIN, Vera. Travessias poéticas. São Paulo: CAPES/EDUC, 2011, p. 367-382. 
luminoso como imagem interior desbloqueada, evidenciando figurações espaciais novas dentro do espaço visto. Portanto, a percepção, enquanto fio articulador da "pensée-paysage", possibilita afirmar que todo ato de transformação do real circundante, em lugares da intimidade, completa seu processo no ato de transferir. Assim, novos territórios do imaginário são demarcados pela pulsão da subjetividade na prática de literatura e outras linguagens dispostas em intersecção.

Se transformada pela presença, a subjetividade vivencia o prazer de sentimentos difratados, incorporando esse novo caleidoscópio de sensações experimenta o dom da palavra como ilusão da paisagem decifrada. Deste modo, sujeitos-poetas, sujeitos-engenheiros, sujeitos-geógrafos e sujeitos-arquitetos convergem nesta concepção da paisagem, hoje, como percepção que seduz pela emergência de relações inesperadas, aquém e além de todas fronteiras disciplinares e discursivas estabelecidas: sob a mediação da Pensée-Paysage, o Sujeito nomeia imagens de infatigáveis transferências e relocalizações de limiares atravessados, em busca da nova paisagem. Acrescente-se que uma dessas possíveis travessias é sugerida na própria reflexão de Haroldo de Campos na configuração do tradutor como: "O tradutor é um coreógrafo dançarino", diz esse poeta e teórico da tradução, retraçando o perfil do Sujeito fazedor e leitor de paisagens pelo prazer do livre dançar. Esse crítico fixa na imagem da dança a matriz da sensibilidade contemporânea; como se, ao efetuar o ballet de formas no espaço, em movimentos de voluntário deslocamento, revitalizada, a subjetividade captasse o lugar e o ato da palavra simbólica a nomear, fundando, certas paisagens primordiais dentro da paisagem primeira. (Leia-se, sob esta imagem do tradutor dita por Haroldo de Campos, a intersecção da "pensée-paysage" com a dança considerada como transformação do espaço exterior pelo livre deslocamento do corpo pensante.)

Poeta do Rio de Janeiro, Ana Cristina César demarca, na cena brasileira, esta eficácia da dança como arquivo vivo da paisagem sensível cartografada pela presença. Em Le Ballet de l'Opera à Rio, dizem os versos de Ana Cristina César:

Dos bastidores perde-se a ilusão do transe, mas hoje eu queria escrever do meio de luzes que só a platéia visse.

desejava um palco puro, pura

perspectiva de platéia. desejava

escrever com violência para consolar-te: a violência com que (imaginamos) 

os bailarinos fetichizados que se erguem
em êxtase
em transfiguração

(César, 2008, p. 118)

Este espetáculo, visto dos "bastidores", ao incidir no efeito de "transfiguração" e ao se fazer o pensamento que rememora a lição de Mallarmé sobre a dança ("La danseuse n'est pas une femme qui danse"), bem como ao figurar a sublimação da neutralidade e da flutuação e ao evidenciar o diálogo que o livre dançar estabelece com o livre pensar, dá a ver a transformação da paisagem exterior em paisagem da subjetividade.

Assim, o simbolismo da dança, nesse poema de Ana Cristina César, estampa o poder de metamorfose produzido pelo jogo efetuado entre paisagem-representação e paisagem-presença ou "pensée-paysage". Nele, o movimento do corpo gera, na cena exterior, uma experiência paisagística distinta para o sujeito-perceptor e fundador de novas paisagens; consiste na descoberta de ângulos até então imperceptíveis de sua intimidade, a mais recôndita, os quais, uma vez descobertos, completam essa experiência subjetiva. Desse modo, a dança configura-se como uma das possíveis representações da "pensée-paysage" vista pelo viés da percepção e de sua ressonância sobre o próprio movimento do espraiar-se da subjetividade. Trata-se de valorizar a força de invenção emergente do espaço intervalar e de equilíbrio entre natureza, cultura e subjetividades contemporâneas, onde diferentes linguagens aproximadas encontram no poema o lugar de novos territórios comparatistas.

Sob a égide desse percurso demarcado pela eficácia da "pensée-paysage", os versos de Manoel de Barros, poeta do Mato Grosso do Sul, constituem, a exemplo da dança, uma outra matriz do livre pensar como livre perceber praticados pela "guinada subjetiva". Traduzindo o frescor quase imaculado da fauna e da flora da geografia pantaneira, pelo sentimento do interior a ser desbloqueado, compõem certo espaço intersticial entre memória residual e memória nova; como se, relocalizado, o sujeito redescobrisse cantos e frestas paisagísticos a explorar e que a subjetividade nomeia, autonomeando-se. Logo, a leitura simbólica dos versos de Manoel de Barros, sob a transparência da "pensée-paysage", realça, com rara poeticidade, o potencial de metamorfose, (ou de "transfiguração", como o desejava Ana Cristina César), e que tanto a dança quanto a geografia do Pantanal concretizam singularmente. Como dizem fragmentos de versos de Uma didática da invenção, de Manoel de Barros: 
Para apalpar as intimidades do mundo é preciso saber:
a) Que o esplendor da manhã não se abre com faca
b) $\mathrm{O}$ modo como as violetas preparam o dia para morrer
c) Por que é que as borboletas de tarjas vermelhas têm devo- ção por túmulos
d) Se o homem que toca de tarde sua existência num fagote, tem salvação
e) Que um rio que flui entre dois jacintos carrega mais ter- nura que um rio que flui entre dois lagartos
f) Como pegar na voz de um peixe
g) Qual o lado da noite que umedece primeiro.
etc
etc
etc
Desaprender oito horas por dia ensina os princípios.
(Barros, 2010, p. 299)

Palavra inventiva, estes versos recartografam o regional, difratando-o em gesto que mostra o deslocar-se de presenças em busca de autotradução: o gesto de se autotraduzir rompe o silêncio e, fazendo-se arquivo certa paisagem invisível, grava sobre a página o prazer que o literário compartilha com certo discurso geográfico poetizado.

Observa-se que, em Manoel de Barros, a invenção como plenitude da "pensée-paysage", ao se articular com base no reaprender, reitera o simbolismo do "educar" de Tenzone de Haroldo de Campos, nele sublinhando o efeito de decantação em que o sujeito se transforma, transformando a paisagem.

Do mesmo modo, Armando Freitas Filho, poeta do Rio de Janeiro, baseando seu fazer poético na sedução eficaz da presença, se, de um lado, também retorna à lição dos Cinco Sentidos, ensinados por Haroldo de Campos, de outro lado, agrega a esse desejo de tornar inteligível o enigma da paisagem do Outro; como se fazê-lo intermediasse o encontro da palavra que incide na valorização do Outro considerado como ressonância projetada sobre a página, em gesto que desdobra a subjetividade do Mesmo. Diz o poeta em versos de Cinco Sentidos:

1

No meu olhar o recorte

da sua figura - sinal :

o afiado gume do corpo

e da linha que o desenha

lento, em cada tempo 
do movimento, sinto

em cada vento, tênue

o móbile de sua presença.<smiles>[AlH2]</smiles>

5

E escapa: mancha de som esparso na qual o ouvido capta o espasmo, o passo da vida, a letra da voz

que se inscreve no sulco no resgate do sangue: degrau sob os panos e sob os sustos do sono escuto seu nome.

(Freitas Filho, 2010, p. 62-63)

Contudo, a imagem mais exemplar da paisagem, como matriz de produção e de expansão do livre pensamento, é expressa nos versos de Adélia Prado. Neles, o desenho de certa paisagem subjetiva subverte a cartografia da "pensée-paysage", primordialmente espacial, pela demarcação temporal:

Há dentro de mim uma paisagem

entre meio-dia e duas horas da tarde.

Aves pernaltas, os bicos mergulhados na água,

entram e não neste lugar de memória, uma lagoa rasa com caniços na margem.

Habito nele, quando os desejos do corpo,

a metafísica, exclamam:

como és bonito!

Quero escavar-te até encontrar onde segregas tanto sentimento.

Pensas em mim, teu meio-riso secreto atravessa mar e montanha, me sobressalta em arrepios, o amor sobre o natural.

O corpo é leve como a alma, os minerais voam como borboletas.

Tudo deste lugar entre meio-dia e duas horas da tarde.

(Prado, 1976, p. 88) 
Nestes versos, onde temporalidades e espacialidades harmonizam-se sob forma de suave convívio, o leitor é brindado com a plenitude da experiência paisagística. Apresenta-se como vislumbre de um ponto intervalar no qual sujeito, subjetividade e geografia simbólica confluem no sentido de perscrutar, na nova paisagem construída, os vestígios emergentes do literário produzidos pela redefinição teórico-crítica do espaço literário consequente do convívio com outras linguagens.

Uma voz poética distinta agrega-se a essa busca do inesperado, na poética do Brasil contemporâneo que colhe da voz de José Horácio Costa um possível mapa dessas modulações líricas, incidindo em percepções memoriais inimaginadas. Justamente nos versos, quando esse poeta diz:

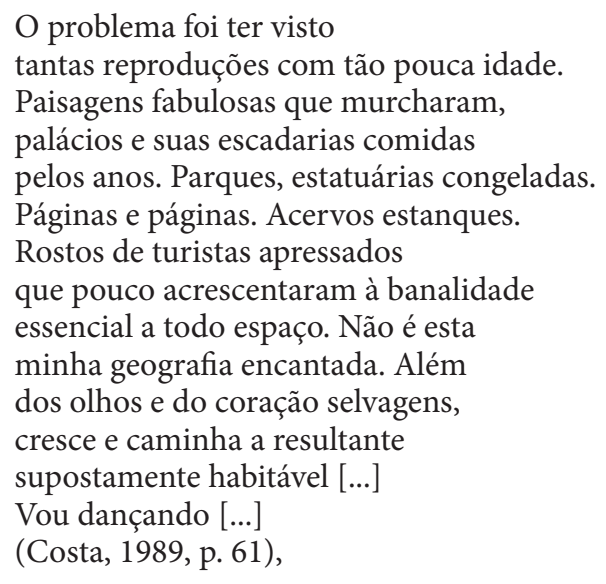

esta imagem da "geografia encantada" consolida a operação de descristalização da paisagem representada; permite ao leitor certo efeito de flutuação; como se o simbolismo de todo flutuar consistisse nessa visitação a este espaço de confluência em gesto que remete tanto à Cartografia Mínima de Marcos Siscar quanto à plenitude do deslocamento que libera o corpo no tempo e no espaço pelo movimento dançante presente nos versos de Ana Cristina César. "Vou dançando", esse verso de Horácio Costas que traduz esse instante de rara sublimação insinua, a seu modo, a multiplicidade de caminhos traçados pela cartografia contemporânea, vistos sob a perspectiva da literatura e outras linguagens dispostas em forma de caleidoscópio.

A leitura simbólica dessa textualidade plural permite observar que estes fios imprimem sustentabilidade, bem como concedem força de irradiação à voz poética, na base da reflexão desdobrada da "pensée-paysage". 
Observa-se, nesse sentido, que a abordagem de Michel Collot instala o Sujeito na paisagem sem figuras, propõe-lhe a decantação da paisagem íntima, constituindo-a como presença (como figura presente) que, pela mediação do exercício do pensamento, promove transferências transgeográficas e transubjetivas, transferências das quais o efeito de ressonância, traduzido pelo entrelaçamento de linguagens literárias e culturais, dá a ver o efeito de sublimação a qual ascende todo leitor de paisagens; como se recortar da exuberância tropical a micropaisagem da leveza, proposta pelos versos de Adélia Prado e já antecipado por Manoel de Barros, sublinhasse, na pesquisa do avesso, do visto, do sentido, do escutado e do enigmático, certa dança de formas esboçando-se em impensáveis figurações, a exemplo do conjunto de mapas poéticos traçados pelos fragmentos apresentados.

Seguindo nesse diálogo inconfesso entretecido por poetas brasileiros contemporâneos, desdobrado da "pensée-paysage", Jardin à la française, do poeta de São Paulo, Marcos Siscar, fixa, neste "pas-au-delà" da cartografia paisagística, linhas descontínuas que dão voz ao pensamento liberado pela poesia pensada; nela, a palavra diz o transbordamento da subjetividade como efeito nomeado pela flutuação:

eu com minha idade sentado num banco de praça
meu coração era do tamanho do mundo
feito do seu elemento de água rumor e ornamento
duas alamedas duas fontes se escorrendo
meu coração era do tamanho deste mundo
ora assim igual a si mesmo ora se
desconhecendo
mas meu coração é menos perfeito do que esta praça
às vezes se lembra e dificilmente
da hora exata do retorno do tempo
meu coração às vezes tropeça projeta uma perna
sobre a outra
se interrompe mudo parece
que pensa

(Siscar, 1999, p. 54)

Inventor e leitor de paisagens, sob a égide deste pensamento que transborda, flutuando, atravessando e reatravessando espacialidades e temporalidades pluralizadas, estes versos de Marcos Siscar recolhem da paisagem a certeza de um duplo fazer: daquele que reúne em um só lugar a vitalidade inesgotável de mitos, temas e motivos gerados pela relação 
voluntária e previsível da literatura com outras linguagens e daquele dos eixos teóricos estruturantes da expressão, produto de linguagens compartilhadas e desejadas por todo poeta contemporâneo nacional, conquanto permitem repensar os mecanismos de seu artesanato formal, configurando-os sob forma de reflexividade e autorreflexividade em constante processo de ressimbolização.

Desenhada pelo simbolismo de espacialidades e temporalidades difratadas, esta paisagem nova estampa uma constelação diversa, mas convergente, no projeto de configurar a produção poética brasileira pela evidência de um ponto de harmonia, tecido pela mescla de distintas formas expressionais, entre dentro e fora, próximo e distante, Mesmo e Outro, ponto de conciliação que assegura ao sujeito contemporâneo o prazer de conciliar o inconciliável, (que este inconciliável refira-se a presenças díspares e pensares artísticos e culturais, postos em intersecção pelo ato de perceber o homem e seu meio pela mediação de um pensamento amplo e transgressivo). Portanto, da linguagem que diz a paisagem geográfica como representação do lugar tropical àquela que nomeia a paisagem como magnetismo da presença que transforma, os poemas evocados transferem e fundam o novo pelo reencantamento da geografia ressimbolizada e, pois, poetizada.

A reflexão de Michel Collot, articulada com base na "pensée-paysage", ao reordenar os estudos paisagísticos pela indistinção de espaço e tempo, propõe ao escritor brasileiro uma percepção outra do imaginário nacional. Aquém e além da celebração da exuberância da fauna e flora tropicais, aquém e além do projeto obstinado de reinvenção do Outro pelo Mesmo, a voz interior inocula na palavra poética o projeto de nomear sobre a página o artesanato do poema, no sentido de traduzir modulações líricas de rara poeticidade (rara configurada como busca, hoje, de demarcar lugares, efeitos artísticos esperados para, pela mediação desse voluntário exercício, abrir espaço à neutralidade). Nota-se que a reflexão de Marcos Siscar sobre os caminhos perseguidos pela produção contemporânea, ao afirmar que:

[...] tout se passe comme si la poésie devrait s'expliquer sur l'impasse de la technique pour pouvoir commencer à parler ; comme si par sa seule manifestation elle devait se mesurer à l'ampleur des questions qui la précèdent. Chez bien de poètes, cette préocupation relève du topos, de sorte que l'inflexion qu'ils donnent à la question du rapport à la formalité (technologique, modernisante, poétique) sert de critère pour juger de l'accès ou non de la poésie actuelle au devenir de sa voix (Siscar, 2005, p. 81), 
expressa, a seu modo, o projeto formal sugerido por Michel Collot, marcado pelo traço de transferência de campos simbólicos a não simbólicos e vice-versa, para os quais a eficácia da "pensée-paysage" funciona, portanto, como mediação que encontra na livre invenção, gerada pela multiplicidade de linguagens que gravitam em torno da literatura a matriz de paisagens novas e primordiais. Verifica-se, em síntese, que a amostragem poética do Brasil contemporâneo converge no desejo de reencantar a geografia, reencantando a própria subjetividade. Desse modo, conclui-se que a "cartografia mínima", de Marcos Siscar, como vestígio de um percurso outro a redesenhar, a imagem da "geografia encantada", desdobrada da voz de José Horácio Costa, a relação do espaço paisagístico com o pensamento em Haroldo de Campos, a figuração da dança como constante reacomodação de certo inquietante pensar em Ana Cristina César, a invenção da geografia ou regionalismo mundializado em Manoel de Barros, a demarcação de certa paisagem intervalar em que a suavidade do traçado de linhas, formas e temporalidades faz-se instante de sublimação em Adélia Prado, e, finalmente, em Marcos Siscar, a imagem de certo pensamento desbloqueado e ampliado pela evocação a uma figuração transnacional expressa já pelo título do poema em francês, Jardin à la française, essas imagens constituem, cada uma a seu modo, perspectivas da paisagem intervalar e multifacetada, produto do cruzamento de diferentes linguagens sobre o espaço literário.

Em uma palavra: a voz que torna esse espaço amplo e polissêmico é a mesma que o torna dispositivo apto a acolher e a reencantar a heterogeneidade da experiência contemporânea artística e cultural. Acolher e reencantar não somente para nomear o impacto exercido pelo prazer de vivenciar novos modos e formas perceptivas pela pulsão do pensamento, mas, também, para traduzir o reencantamento da voz interior que, ao decifrar espaços aparentemente indecifráveis e obscuros de sua subjetividade profunda, completa essa prática de descoberta, transformando o real circundante em paisagem da intimidade. Geografia subjetiva e geografia territorial entrelaçadas fazem-se, pois, desenho potencial de novas cartografias para o pensamento paisagístico, hoje. "Pensée-paysage" como itinerário de novos mapas e de atlas discursivos desenhando relações entre Poesia, Paisagem e Memória. Desse modo, sob as palavras de Michel Collot, quando diz: "Le paysage porte les traces d'une mémoire qu'il convient de ne pas effacer, mais d'entreprendre à lire et à interpréter, pour inscrire l'action du paysagiste dans la continuité de celles qui ont contribué à le façonner", enquanto evidência de continuidade e transformação de que se reveste toda paisagem, lê-se o ajuste teórico-crítico da "pensée-paysage" na expressão da voz-síntese de Marcos Siscar, ao dizer: 
La vitalité inouie de la poésie brésilienne, que l’on constate aujourd'hui dans les revues, à travers la circulation des lectures et des opinions, doit nous rendre attentifs à ce qui peut avoir lieu [...] la poésie reste un lieu de promesse et de maturation de ce qui advient (Siscar, 2005, p. 91).

Sob a transparência de literatura e geografia ressimbolizadas, a percepção desse entrecruzamento teórico-crítico legitima a abrangência infinita a que remete Cartografia Mínima, poema último de Manual de flutuação para amadores, poema, ao mesmo tempo, que se faz matriz inaugural para a leitura da produção nacional. Poesia Brasileira, Paisagem e Memória das quais o diálogo de ininterruptos desdobramentos configura-se como arquivo vivo e potencial para o estabelecimento de relações outras entre literatura e outras linguagens.

\section{REFERÊNCIAS}

BARROS, Manoel de. Poesia completa. São Paulo: Leya, 2010. BERWANGER DA SILVA, Maria Luiza. "Littérature Brésilienne Contemporaine: entre production et reflexion". In: BESSIÈRE, Jean (Org.).

Littérature d'aujourd'hui : contemporain, innovatiom, partages culturels, politique, théorie littéraire. Paris: Honoré Champion, 2011, v. 17, p. 77-84. . "Autorreflexividade e Invenção na Poesia Brasileira Contemporânea”. In: BASTAGIN, Vera. Travessias poéticas. São Paulo: CAPES/EDUC, 2011, p. 367-382

CAMPOS, Haroldo de. Léducation des cinq sens (A educação dos cinco sentidos). Trad. de Luiz Carlos de Brito Rezende. Paris: Plein Chant, 1989. . A educação dos cinco sentidos. São Paulo: Iluminuras, 2016. [lançamento previsto para setembro do ano em curso] CÉSAR, Ana Cristina. Antigos e soltos - Poemas e Poesias da Pasta Rosa. Rio de Janeiro: Instituto Moreira Salles, 2008. COLLOT, Michel. La Pensée-Paysage. Paris: Actes Sud/ENSP, 2011. . Poética e filosofia da paisagem (Coordenação da tradução: Ida Alves). Rio de Janeiro: Oficina Raquel, 2013. COSTA, José Horácio. Satori. São Paulo: Iluminuras, 1989. DROIT, Roger-Pol. La taille de l'expérience : Introduction à la taille de l'expérience, de Julia Kristeva. In : KRISTEVA, Julia (Org.). Donner à penser. Paris: Centre Roland Barthes / Éditions du Seuil, 2005. p. 151-182. FREITAS FILHO, Armando. Melhores poemas. São Paulo: Global, 2010. 
PRADO, Adélia. Poesia reunida. São Paulo: s. n., 1976.

SARLO, Beatriz. Tempo passado. São Paulo: Companhia das Letras, 2007. SISCAR, Marcos. Littérature du Brésil. Revue Europe, n. 919-920, 2005. . Manual de flutuação para amadores. Rio de Janeiro: 7 Letras, 2015. . Não se diz. São Paulo: Sete Letras, 1999.

Recebido em: 12/05/2016. Aceito em: 30/08/2016. 